Trakia Journal of Sciences, Vol. 17, Suppl. 1, pp 758-763, 2019

Copyright (C) 2019 Trakia University

Available online at:

http://www.uni-sz.bg

ISSN 1313-7069 (print)

ISSN 1313-3551 (online)

doi:10.15547/tjs.2019.s.01.124

\title{
SOME CHANGES IN THE PSYCHOMOTORISM OF STUDENTS WITH DIFFERENT LEVELS IN MOTOR ACTIVITY
}

\author{
L. Kasabova* \\ Department of Physical Education and Sport, Business Faculty, \\ University of National and World Economy, Sofia. Bulgaria,
}

\begin{abstract}
Hypodynamia and hypokinesia are the main cause of decreased motor activity among students, resulting in lower vital parameters, deterioration in health and lowering the learning abilities. The quality of the physical education process in the higher school levels depends to a large extent on the psychological processes of the trainees. In the study we aim to identify some features of psycho-motor characteristics and to compare the level of learning of the total study material in students with different levels of motor activity. The following methods that were used: analysis of literary sources, sports-pedagogical experiment, sports-pedagogical testing, and mathematical-statistical analysis. Sixty (60) UNWE students were divided into two groups. The first one includes those who regularly participate in sport classes and the second one is formed by students not regularly attending those activities. The results of the study show that regular sports activities have a positive impact on the concentration of thought processes. Improvements in the psycho-motor of motor activity in students, lead to an increase in their activity during the educational and work process. We encourage students to attend regular physical education classes and practice sports in their spare time.
\end{abstract}

Key words: Students, psycho-motor indicators, unsporting, success rate

\section{INTRODUCTION}

For the living organism, movement is a physiological need, the failure to meet this need over a long period of time leads to serious deviations in the health of the person. Undeniable is the fact that sport is the social phenomenon of modern society (1).

Insufficient physical activity (hypodynamia) and lack of muscle movements (hypokinesia) are the two varieties of inadequate motor activity, which are the main reason for the decrease of life activity. The parameters of the vital activity of the brain, the internal organs, the respiratory as

*Correspondence to: Larissa Kasabova, Department of Physical Education and Sport, Business Faculty, University of National and World Economy, Sofia 1700, December 8th Blvd. Bulgaria,phone: (+359) 888369952; (+359 2) 86290 75, e-mail: larissa.kasabova@gmail.com the physical, mental and social development of young people". Others believe that: "The physical and mental qualities of a person develop or fall greatly under the influence of working conditions and lifestyles" $(3,4)$. Other author (5) point out the importance of participating in a sporting event as a "provocateur" for revealing personal qualities. A number of sports professionals ask, "Is the rational use of physical exercise and sports used to improve the health, physical development and physical capacity of our youth and in particular the students $(4,6,7)$ ? Science defines different modes of physical activity - maximum, optimal and minimal. While the optimal mode is the highest level of the body's functional capabilities, the minimum range only allows the body's functional status to be maintained. Nowadays there are practically no specialized complex studies of the functional and individual psychological and psychomotor 
characteristics of students with different physical preparedness. In this regard, we aim to identify some features of the psychomotor characteristics of students with varying degrees of motor activity.

The entire psychomotor activity of the living organism is governed by the central nervous system (CNS) and this is the priority of the thinking subject - the human being. The presence of the somatic and vegetative nervous system in it enables him to receive continuous information about the state of his internal organs and systems as well as about the change of the external environment. The two systems are inextricably interconnected while the first one provides information about the state of the internal organs, the second one is the supply of the metabolism and transport of the energy necessary for the motor actions (8).

Gavriiski (9), draws particular attention to the fact that analysts are the ones who realize the accurate and timely perception of incoming signaling coming from the external and internal environment and provide opportunities to react through a motor activity defined by the capabilities of the organism. According to Mateev, (1962) the strength of the response of the working muscle or body depends on the axons involved in the action inerting these working systems.

More $(10,11)$, have proved that the sending of afferent messages to the CNS with the help of nerve pathways is a complex process involving all analysts taking part in the senses. At the same time, the CNS receives information about the body's visual, tactile, skin, vestibular, motor and other sensor systems. This is done with the help of the receptors, each analyzer having its own receptors, excited individually to the so-called „Threshold of irritation", $i$ that minimal irritation that causes excitability of the analyzer. The activity of analysts has been well studied, but what is most important, especially for sports, is that they are subject to development, improvement and continuous improvement (9).

On the other hand, the quality of the learning process or level of sport activity depends to a large extent on the psychological processes that arise in man. For example, Dimitrova, (12) considers that the concentration of attention during the study of a theoretical material depends to a great extent on the intensity, concentration, distribution and switching ability of attention. Accuracy in musculoskeletal activity, according to Viru (13), is modified several
KASABOVA L.

times with the help of training, and the state of motion psychomotorics implies significantly more accurate movements, for example in technical drawing, drawing and other work activities. Some studies by our authors $(14,12)$ show that students with higher psychomotor performance are doing much better in the learning process than those who do not practice and do not engage in sports.

In other studies $(13,15,8)$ found that the adaptability of the body to physical or mental stress was associated with certain "depressions" cerebral cortex, which leads to "crashes", disco-ordination in the operation of the motor apparatus, reduction of the working capacity and adaptability of the body in case of insufficient training.

More autors (15-17) studied the psychomotorics of students, finding that regular twice-weekly students have higher academic success than non-sporting ones.

\section{OBJECTIVE, TASKS, ORGANIZATION AND METHODOLOGY OF THE STUDY}

The purpose of our study, namely: to identify the changes in some psychomotor indicators in students attending regular physical education and sports classes and students who for various reasons are freed and have not attended these activities.

The objectives of the survey are as follows:

1. Establish the initial (output) indicators of certain psychomotor tests at the beginning of the school year.

2. Registration of the endpoints from the psychomotor tests conducted at the end of the school year.

3. Comparing the performance of the indicators with the learning outcomes of the study material by the students included in the two groups, through the level of overall success achieved during the examination sessions

\section{SUBJECT OF STUDY}

The individual psychomotor indicators of students with different levels of physical activity were examined using eight tests through which we followed the changes of ten indicators in first and second year students, regular training at UNWE.

A total of 60 students are divided into two groups: the first (I) of practitioners regularly in physical education and sports, and the second (second) of students freed or not attending these classes regularly for various reasons. The groups are composed of 30 students each. 


\section{METHOD OF RESEARCH}

The study was conducted during the winter and summer semesters of the 2017-2018 school year. As the first (I) group works on the approved curriculum of the course „Physical Education Basketball" and the second is composed of nonattending students.
KASABOVA L.

For the purpose of the study, within the sportpedagogical experiment, (twofold) sportspedagogical testing was conducted at the beginning and end of the experiment.

In our research we used the following methods: analysis of literary sources, sports pedagogical experiment, sports-pedagogical testing, mathematical statistical analysis.

Table 1. List of indicators included in the test battery for sports-pedagogical testing

\begin{tabular}{|c|l|c|c|c|}
\hline № & \multicolumn{1}{|c|}{ Indicators } & & & \\
\hline 1. & Manual Dynamometry & $k g$ & 1,0 & + \\
\hline 2. & Muscle differentiation & $m$ & $\mathbf{0 , 1}$ & - \\
\hline 3 & Accuracy when applying force & $k g$ & 1,0 & $+/-$ \\
\hline 4. & Testing test - upper limb & piece & 1,0 & + \\
\hline 5. & Frequency of Lower Leg Movements & piece & 1,0 & + \\
\hline 6. & Tremorous hand & piece & 1,0 & - \\
\hline 7. & Burdon Test Correctness $(\boldsymbol{k})$ & $K$ & $\mathbf{1 , 0}$ & + \\
\hline 8. & Bourdon Test - Focus of Attention $(\boldsymbol{k})$ & $K$ & 1,0 & + \\
\hline 9. & Speed of the simple motor reaction & $m s$ & $\mathbf{0 , 1}$ & - \\
\hline 10. & Ideal Thinking) & $s$ & 1,0 & $+/-$ \\
\hline
\end{tabular}

1. Manual dynamometry - using a manual original dynamometer

2. Muscle differentiation -Muscle resolution for the applied upper limb force: Three circles with a diameter of $60 \mathrm{~cm}$ are outlined at 10,12 and 15 meters from the starting line. The investigated person performs two attempts to score a $2 \mathrm{~kg}$ thick ball. in each round. Measure the difference of the hit to the center of the circle in centimeters.

\section{Accuracy when applying force}

Power applying force -Dynamic Dynamometer with the help of a manual dynamometer of the examined person is assigned the task of squeezing the dynamometer with $30 \%$ and $70 \%$ of the maximum.

4. Upper limb topping test: On a mass of $60 \mathrm{~cm}$ each, two circles with a diameter of $25 \mathrm{~cm}$ are drawn from each other. The experienced person on a signal starts moving one hand as fast as possible, touching one and the other round for 20 seconds. The number of touches in both rounds is counted.

5. Frequency of Lower Leg Movements: The experienced person stands in front of a wall without resting on it. By signal begins to tap with the tip of his fingers on the wall for 20 seconds. The number of knocks is counted.

6. Tremble of the hand: Two metal strips, $25 \mathrm{~cm}$ long, connected to a battery, are mounted on a wooden stand. The experienced person facing the device seeks to push the beam of the phasmometer without touching the metal strips. On a special counter are reported the wrong touches to the cash tapes.

BURDON Test. 30 vertical and 18 horizontal lines containing six types of geometric shapes, three in each row, are printed on a sheet. The experienced person strives to mark a specific geometric body and to trace as many pieces as possible for one minute.

7. For correctness, the relationship between the total number of figures to be skewed minus the total number of errors multiplied by one hundred and divided by the total number of figures to be skewed is taken into account. A success rate is displayed.

8. For the focus of attention, the test is initially performed without external stimulus interference, and secondly with one such that the experienced person is talking or delivering a loud sound signal. Calculate the difference in offsets in the first and second tests.

$\mathbf{K}=\mathbf{2 C} / \mathbf{P}$, where

$\mathbf{C}$ - number of rows of the form examined by the investigated person;

$\mathbf{P}$ - number of errors (missed or incorrectly labeled characters);

9. The speed of the simple motor reaction. The experienced person holds an electronic stopwatch in his hand and strives after a signal to start and stop the stopwatch as quickly as possible. Two attempts are made, taking the better result in milliseconds. 
10. Ideal thinking. The tester teaches the experienced person to stop the chronometer of the fourth and ninth second after it is released, without visual control. The difference between the two exercises (stops) is recorded.

\section{RESULTS AND ANALYSIS}

The results obtained were processed using the variance analysis (19).

The changes in the indicators adopted in our study are shown in Table 2.

The two groups of students studied have approximately the same baseline values of the test scores as the nature of the study allows.

The average values for the first indicator (manual dynamometer) in both groups are subject to certain
KASABOVA L.

changes. The growth in Group I of sports students in absolute terms is significantly higher $(4.1 \mathrm{~kg})$ than that of non-sports students in Group II (1.4 $\mathrm{kg})$. This is an anticipated change, as a variety of exercise exercises with and without appliances are $i$ ncluded in the program. The coefficient of variation $(\mathrm{V})$, which expresses distraction as a percentage of the mean values of the signs, is significantly lower in both the theoretically offered in the literary sources. For values „V" up to 10 $12 \%$, the sample is considered to be highly homogeneous and can be considered as meaningful. In our study, the „V" values obtained are significantly below the required minimum for "satisfactory homogeneous" values, making dispersion around the average relatively low.

Table 2. Changes in psychomotoism of students with different levels in motor activity

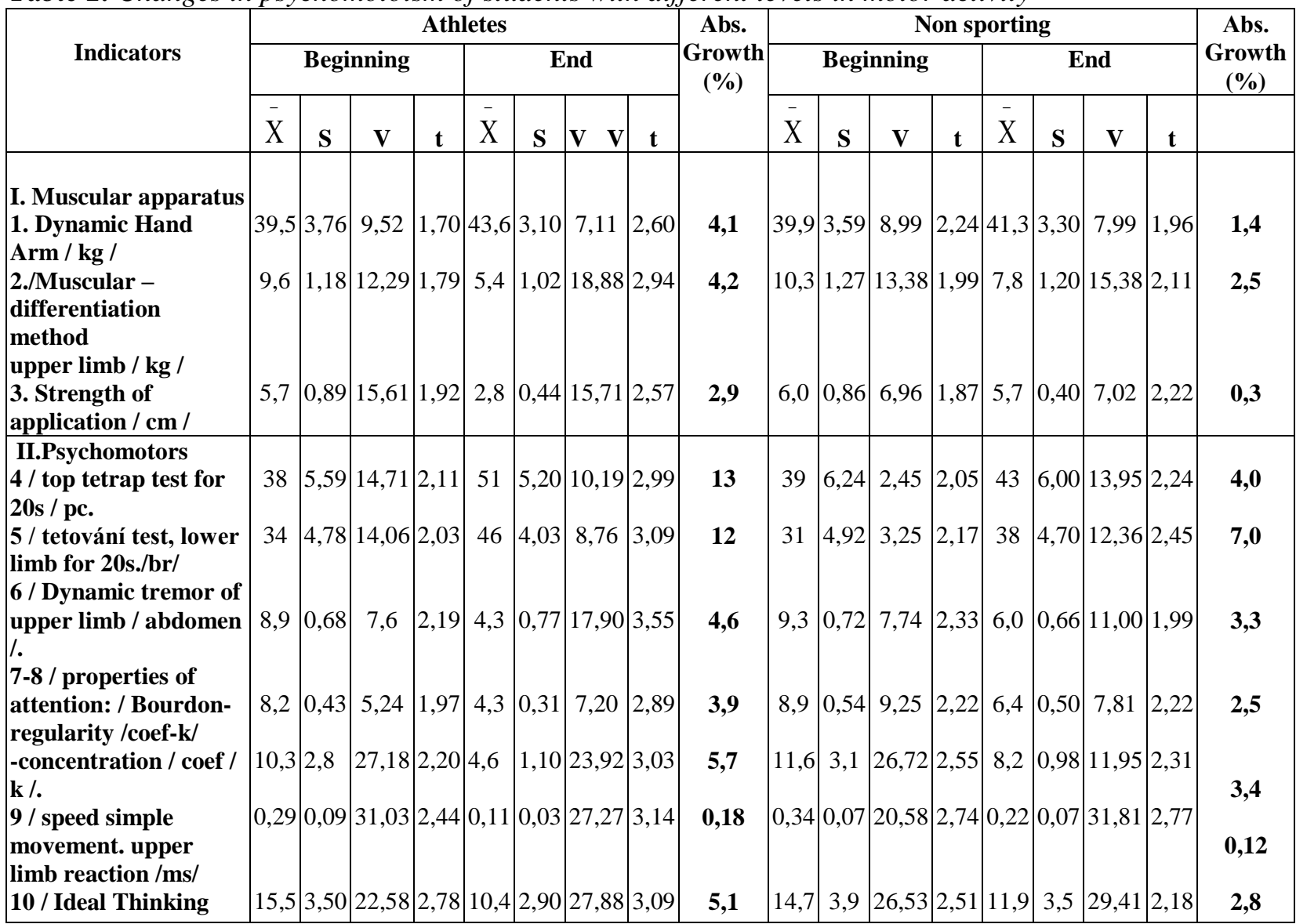

This applies to both groups, which suggests that the selected test parameters are biologically suited to the individual, is not influenced by the level of the trained, but the level of the test increases significantly.
Indicators 2 and 3 for the trainer show the importance of physical exercise to improve muscular sensitivity and the ability to apply significantly more measured force in size. While the baseline data in the two groups at the start of the study were close, at the end of the study, the success rate of the trainers was nearly twice as high. 
The magnitude of the standard deviation, as an indication of the dispersion of the individual cases around the arithmetic mean $(\overline{\mathrm{X}})$ in both groups, varies in approximately close range. The second scattering indicator - the scattering factor is slightly higher for sportsmen, which can be considered as an individual response of each student's body due to the effect of applying physical stresses on it.

The seven psychomotor parameters characterizing the state of the musculoskeletal apparatus in practitioners of sport with certain physical stressed students have even more pronounced expression than those who do not practice sport.

The upper and lower limb test in the 1st group improved with 13 and 12 knocks respectively, while in the second group it was only 4 and 7 knocks.

Dynamic tremor (Indicator II-c) is also better in first group, but in absolute terms it is 1.3 lower in the second group. This is probably due to the increased muscular excitability of the neuromuscular apparatus due to the physical load.

The endpoints of the $\mathrm{S}$ and $\mathrm{V}$ indicators as an expression of the variance of the dissection of the individual cases are close in importance and again
KASABOVA L.

indicate that they are due to the putative genetic formation of the organism.

The attributes of attention, such as "correctness" and "concentration," are influenced by the motor activity performed in Group I. With close baseline data, the growth in sports is $55-57 \%$ higher than that of the second group, which also saw an increase of $28.7-29.2 \%$. Since these two characteristics characterize the state and activity of the central nervous system and the analyzers, improving them shows that increased motor activity supports the development of mental processes, improves the intensity, concentration and efficiency of CNS work.

The speed of the simple motor reaction in the two groups does not undergo significant changes, although it has little advantage for the sportsmen, which shows its natural condition to which many authors draw attention $(8,10,11)$.

The sense of control over the duration of the time interval investigated with the help of the ideological test showed a stronger development among the sportsmen. The absolute improvement of 5.1 seconds is almost twice higher than that of the second group (2.8 s). Here too, the two indicators for the dispersion of cases around the average level of indicators are lower for the first.

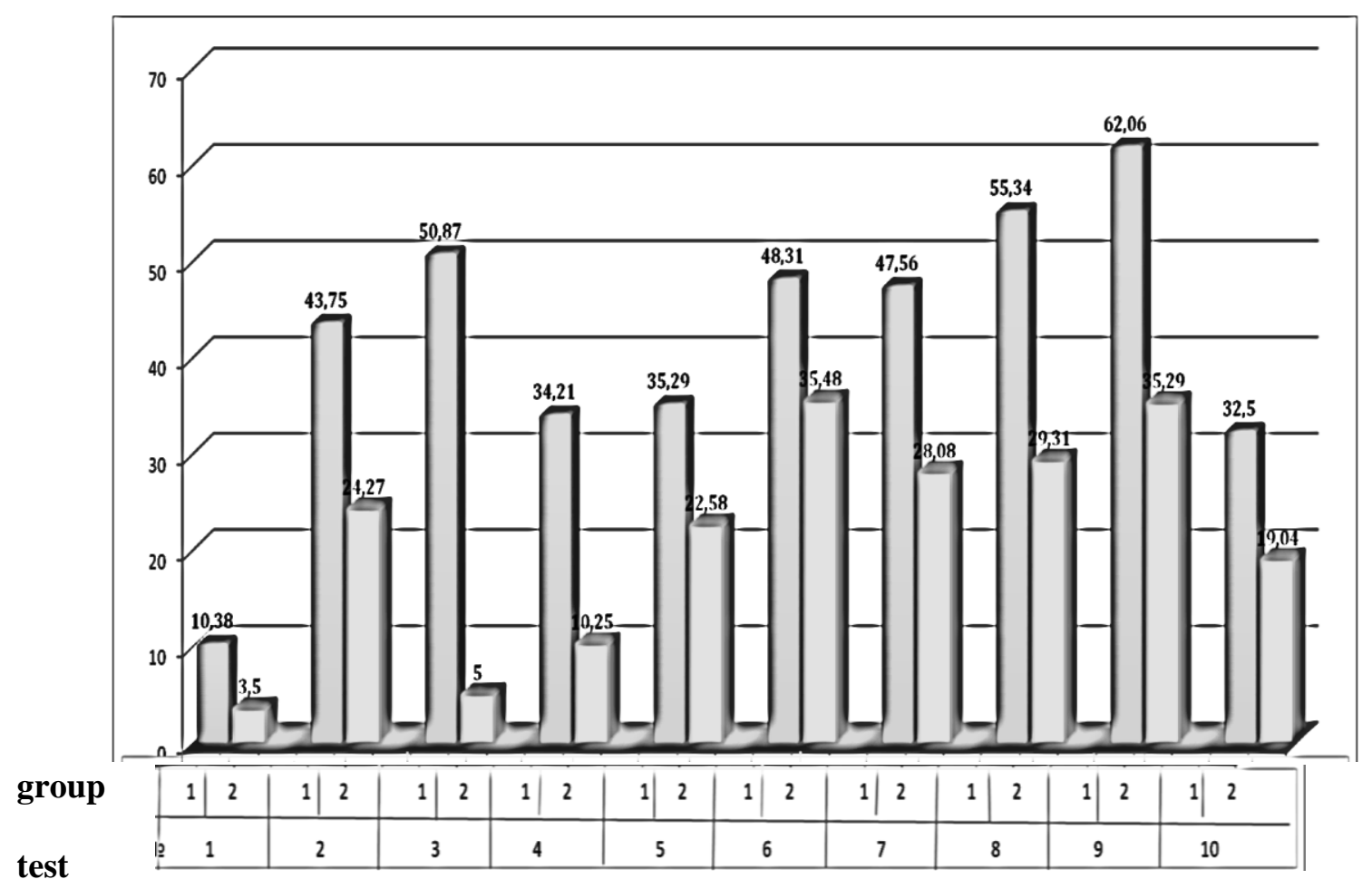

Figure 1. Relative share (\%) in the indicator growth in sporting (1) and non-attendant (2) students from UNWE 

Changes in the level of indicators are also seen in Figure 1, where the level of the relative share of the increase in all group I tests is higher than that of the second group.

Another area in which we sought a correlation between the motor activity and the psychomotor qualities of the students is that related to the learning process. At the end of the first school year, the average success of the sportsmen was very good (4.74), while not sportsmen were good - 4.04. The more successful students have a greater discipline, better allocate their free time, are more active in solving work and learning activities, which distinguishes them from nonsportsmen.

\section{CONCLUSIONS AND \\ RECOMMENDATIONS}

1. The research has confirmed the view of a number of scientists that regular physical exercises contribute to increasing the depth and concentration of thought processes.

2. Improvements in the psychomotorics of motor activity in students lead to an increase of their activity during the educational and labor process. The psychological effect is achieved not only by the work with physical exercises but also by their preliminary targeting, the selection of means and methods for conducting the Physical Education classes with the students.

3. The index of indicators in the I (experimental) group reveals a specific relationship between the level of physical, psychomotor and mental abilities of the students.

4.We recommend not exempting students from FBI activities and sports departments, departments and pedagogues to find and use approaches to encompass students with health abnormalities to stimulate physical activity and motivation of students to engage in sports in order to achieve greater and more effective physical capacity to improve their health.

\section{REFERENCES}

1. Stoilov, I., Investigation of specialized methodology for preparation in futsal., Autoreferat, NSA, S., pp.1, 2013

2. Peltekova, I., "Monitoring the Physical Activity in the Everyday Life of the Young Generation", "Pedagogical environment at the university as a space for professional and personal development of future specialists", Ed. EKS-PRESS, Gabrovo, pp.555-557, 2010

3. Bojkova, A., Analysis of motor skills in the structure of the profession of kinesitherapist. Sat. Publishing complex - UNWE, pp. 132142, S, 2017.

4. Tzarova, A. Basketball in the higher schools in Bulgaria. Monographic work, Ed. "Bolid ins", Sofia, 2017
5. Peltekova, I., "Student Basketball Competitions at Sofia University as a Tool for Personal Development". Sat. Fourth International Scientific Conference "Contemporary Trends of Physical Education and Sport", Sofia, Department of Sport, Sofia, IM “St. Kl. Ohridski “, pp. 104-108, 2012.

6. Stoyanova, S., Development of Physical Fitness of Students from the University of National and World Economy, by Train Training of Comb Bicycle Gauge., Autoreferat, NSA, S., p.1, 2016

7. Mavrudiev, P. Characteristics of Physical Development of Students. // Sports and Science, num. 5, 2018

8. Dobrev, D. and all., Basics of Sports Workout. Ed. NSA "B. Levski “. S., 1998

9. Gavriyski, V., The Electroretinogram of the Healthy Man Examined at Rest and Physical Exercise. Dissertation, Prof., VIF "G. Dimitrov, S., pp. 45-47; 1968

10. Pavlov, I. P. (1949). Conditioned reflex. Full assembly Proceedings, M., t. III, pp. 551-557, 1949

11.Sechenov, I.M.. Reflexes of the brain. Ed. AN-USSR, M., t. I, p. 7-48, 1952

12. Dimitrova, Sv. An attempt to study the connection of sport with the intellectual activity of the individual, "Scientific papers of the VIF", p. 29, pp. 71-75; 1989

13. Viru, A, Generalization in the activity of endocrine jelly with the emotions accompanying sports competitions, Sat. Problems of sports psychology “, FIS, M., pp. 90-95, 1969

14. Mutafova, Y., Socio-psychological characteristic of the sports team as a small group. Socio-psychological characteristics of the sports team as a small group. 2nd Edition, Avangard Prima, S., 2004

15. Popescu, S., D. Dimitrescu, Studying the fluctuations in the fitness of athletes in physical and mental efforts according to the biorhythm theory. Sat. Psychology and Contemporary Sport, MiF, S., pp. 280-282, 1975;

16.Zhelyazkov, Ts., Theory and Methodology of Sports Training, S., MF, 1986

17.Zlatarova, Y., A. Dimitrov, Changes in motor skills of students after specific physical loads. Sat: „Physical education and sport between two centuries", VTU, VT, 95-101, 2000

18. Dimitrov, D. Improving the physical qualities of the students from the University of Forestry. Sat. reports "Young Scientist", LTU; pp. 178-183, 2002

19. Brogli, Y., D. Petkova. Systematization of research data and probability distribution. Ed. NSA “In Levski” S. p. 30-43; 198 